\section{A ordem e a função do clítico SE no português clássico}

The order and the function of the clitic SE in the classical portuguese

Eloísa Maiane Barbosa LOPES (UESB) eloisamaiane@gmail.com

Cristiane NAMIUTI-TEMPONI (UESB) cristianenamiuti@gmail.com
LOPES, Eloísa Maiane Barbosa; NAMIUTI-TEMPONI, Cristiane. A ordem e a função do clítico SE no português clássico. Entrepalavras, Fortaleza, v. 7, p. 151-169, ago./dez. 2017.

Resumo: O clítico SE se destaca dos demais clíticos por apresentar um comportamento diferente, pois, enquanto os outros clíticos estão associados à função sintática de objeto, o SE se associa às funções de sujeito ou objeto. Baseados em Brito, Duarte e Matos (2003), caracterizamos três tipos de SE associados às funções sujeito e objeto: SEPassivo, SE-Indeterminado e SE-Reflexivo. Neste artigo, apresentamos uma descrição do uso do clítico SE nas construções finitas em orações principais neutras, com 0 objetivo de observar a possível existência de uma relação entre a posição e o tipo/ função desse clítico em textos de autores portugueses nascidos nos séculos XVI, XVII e XVIII, período que compreende a gramática do Português Clássico, extraídos do Corpus Tycho Brahe. O uso de SE associado à função sujeito, SE-Passivo e SE-Indeterminado, nas orações principais neutras, parece favorecer a colocação enclítica nos contextos de variação, mesmo nos séculos XVI e XVII, em que a frequência de próclise é superior, pois, na distribuição do tipo de SE pela colocação, a frequência de ênclise para esses dois tipos de SE mantém-se bastante elevada nos contextos de variação ênclise/ próclise, o oposto acontece com o SEReflexivo que mantém elevada frequência de próclise e ênclise marginal.

Palavras-chave: SE-Indeterminado. SEPassivo. SE-Reflexivo. 
v. 7 (2) $151-169$ ago/dez 2017

Abstract: Among the clitics, the SE is noteworthy for presenting a different behavior: while the other clitics are associated to the object function, SE can be associated to the subject or object. Based on Brito, Duarte and Matos (2003), we characterize three types of SE associated with the subject and object function: the passive SE, indefinite SE and SE as a reflexive pronoun. In this paper we describe the use of clitic $\mathrm{SE}$ in neutral main clauses, with the objective of observing the possible existence of a relationship between the position and the type/function of this clitic in texts by Portuguese authors born in the sixteenth, seventeenth and eighteenth centuries, from the Tycho Brahe Corpus. The use of SE associated with the subject function, passive SE and indefinte SE, neutral main clauses, seems to favor the enclitic placement in variation contexts, even in the sixteenth and seventeenth centuries, in which the frequency of proclisis is superior, because, in the distribution of the type of SE by placing, the frequency of enclisis for these two types of SE remain quite high in the contexts of enclisis/proclisis variation, the opposite happens with the SE as a reflexive pronoun that keeps high frequency of proclisis and marginal enclisis.

Keywords: SE as a passive pronoun. SE as an indefinite pronoun. SE as a reflexive pronoun.

\section{Introdução}

A Linguística Histórica é um ramo da linguística bastante produtivo que, apoiada no quadro gerativista, busca analisar as mudanças da língua no decorrer do tempo, além de apresentar a história e a organização da língua no passado. O desenvolvimento de novas tecnologias para o tratamento de textos antigos, relativas à transcrição, à edição, à anotação e à disponibilização desses textos em meio digital, ampliou e intensificou as pesquisas linguísticas na perspectiva diacrônica. No Brasil, os trabalhos com o Corpus Histórico do Português Anotado Tycho Brahe ${ }^{1}$ (doravante CTB) procuram investigar o passado da língua portuguesa, mais especificamente, do português europeu e do brasileiro; além de propor estudos comparativos entre essas duas variantes da língua, principalmente, em relação à colocação dos pronomes clíticos.

Conforme Galves, Namiuti e Paixão de Souza (2006), a variação na ordem dos clíticos na história do Português é um dos aspectos relevantes para entender as mudanças ocorridas na gramática dessa língua. De acordo com as autoras, na diacronia do Português falado em território europeu, é possível identificar, a partir de estudos acerca

\footnotetext{
${ }^{1}$ O Corpus Histórico do Português Anotado Tycho Brahe é um corpus eletrônico do Português, morfologicamente e sintaticamente anotado, composto de textos escritos em português por autores nascidos entre 1380 e 1845. Este corpus foi desenvolvido no âmbito do projeto Padrões Rítmicos, Fixação de Parâmetros \& Mudança Linguística (Fases I e II) sob a coordenação da Profa. Dra. Charlotte Galves (IEL/UNICAMP) e está disponível na rede mundial de computadores, a partir do endereço: http://www.tycho. iel.unicamp.br.
} 
da colocação dos pronomes clíticos, três etapas diferentes quanto ao padrão na ordem dos clíticos pronominais, a saber, três gramáticas distintas, sendo essas: a gramática do Português Arcaico (doravante $\mathrm{PA}$ ), que compreende os textos escritos entre 1200 e 1400, na qual a ordem enclítica era predominante; a do Português Clássico ou Médio (doravante $\mathrm{PCl}$ ), emergente já a partir do século XIV até o XVIII - em que prevalece a ordem proclítica - e a do Português Europeu Moderno (doravante PE), representada pelos textos a partir do século XIX, na qual a ênclise é categórica. Deste modo, Galves, Namiuti e Paixão de Sousa nos explicam que o português europeu, ao longo do tempo, passou de um padrão enclítico para proclítico e novamente do padrão proclítico para enclítico, sendo que a ordem proclítica, frequente no $\mathrm{PCl}$, ou português intermediário, permanece em uma outra gramática, a do Português Brasileiro (doravante PB).

Entre todos os tipos de clíticos, o SE possui um comportamento singular, visto que, além de variar quanto a sua ordem, ele varia, também, quanto à função sintática, podendo estar associado à função sujeito, SEIndeterminado e SE-Passivo, ou à função objeto, SE-Reflexivo; o que o difere dos demais clíticos verbais que são, exclusivamente, acusativos ou dativos, enquanto o SE desempenha função nominativa e acusativa.

Destarte, tendo em vista as particularidades do clítico SE, principalmente, no que tange às funções sintáticas que ele pode exercer ou estar associado na sentença, neste artigo, nosso objetivo é apresentar, dentro do quadro teórico da Gramática Gerativa (doravante GG), uma descrição das construções com SE, em que observamos o uso e a função sintática do pronome clítico SE (sujeito/objeto) em construções finitas, relacionados com o fenômeno da colocação de pronomes clíticos (próclise/ênclise) em textos portugueses, extraídos do Tycho Brahe, escritos por autores nascidos em Portugal entre os séculos XVI a XVIII, período que compreende a gramática do $\mathrm{PCl}$. Este trabalho retoma aspectos da dissertação de mestrado "Um estudo diacrônico sobre a ordem e a função do clítico SE no Português Clássico” (LOPES, 2016). ${ }^{2}$

O artigo $^{3}$ está organizado da seguinte forma: na primeira seção, apresentamos algumas definições acerca dos tipos de SE indeterminado,

${ }^{2}$ Dissertação de Mestrado em Linguística, por nós defendida em 2016, no PPGLIN Programa de Pós-Graduação em Linguística da Universidade Estadual do Sudoeste da Bahia (PPGLin/UESB), sob a orientação da Profa. Dra. Cristiane Namiuti Temponi.

3 Os resultados aqui apresentados são oriundos de pesquisa realizada no âmbito dos projetos Fapesp 2012/06078-9, Fapesb APPo007/2016 e APP0014/2016, CNPq 471753/2014-9. 
v. 7 (2)

151-169 ago/dez 2017

passivo e reflexivo e, consequentemente, das funções desempenhadas por eles de acordo com duas perspectivas teóricas diferentes: a tradicional e a gerativa; na segunda seção, tratamos da sintaxe dos clíticos na história do português; na terceira seção trazemos um breve resumo a respeito da metodologia utilizada para a busca e classificação dos dados, o que engloba a seleção dos textos, a classificação e a quantificação dos dados; na quarta seção, descrevemos as ocorrências com o SE em orações principais, observando a possível relação entre o tipo de SE e a sua ordem na sentença, reservando para a última seção algumas considerações finais.

\section{SE-Indeterminado, SE-Passivo e SE-Reflexivo: abordagens tradicional e gerativa}

O clítico SE, em relação aos demais tipos de clíticos, apresenta particularidades quanto à função sintática que desempenha no interior da sentença, o que o distingue dos outros clíticos, visto que esses desempenham a função objeto, sendo, exclusivamente, acusativos e/ou dativos. O SE pode estar associado tanto à função de sujeito, quando passivo ou indeterminado, quanto à função de objeto, quando reflexivo, podendo ser nominativo ou acusativo. Diante disso, nesta seção, mostramos algumas definições a respeito desses tipos de SE em duas perspectivas distintas: a da Gramática Tradicional (doravante GT), a partir das concepções extraídas das gramáticas de Bechara (2004), Cegalla (2010) e Cunha e Cintra (1985); e da GG, a partir das definições de Brito, Duarte e Matos, na gramática descritiva gerativista de Brito, Duarte e Matos (2003), e das discussões de estudiosos que se propuseram a investigar o clítico SE em suas diferentes facetas, como Galves (1986), Nunes (1990) e Gomes (2007). Além disso, resumimos o percurso diacrônico das ocorrências com SE na história do Português, tendo como base os estudos de Chociay (2003), Cavalcante (2006) e Antonelli (2007).

Em uma perspectiva tradicional, o pronome átono SE pode aparecer na frase como um índice de indeterminação do sujeito, quando representa o sujeito da sentença em verbos intransitivos e transitivos indiretos; é um pronome apassivador, quando forma a voz passiva pronominal ao se juntar a verbos transitivos diretos; e um pronome reflexivo, quando exerce a função sintática de objeto direto ou indireto de verbos reflexivos e reflexivos recíprocos. 
O SE é caracterizado como índice de indeterminação do sujeito, tradicionalmente, por este ser a representação de um sujeito que não está expresso, lexicalmente, na sentença; assim, o SE assume a função de sujeito. Para Bechara (2004), as construções de SE-Indeterminado são as em que não aparece substantivo, claro ou subentendido, funcionando como sujeito do conteúdo predicativo em verbos de $3^{\text {a }}$ pessoa, transformando-as em construções impessoais, exemplo (1) ${ }^{4}$. Cegalla (2010), tal como Bechara, limita-se a definir o SE como índice de indeterminação do sujeito quando este ocorre, obrigatoriamente, nas sentenças em que o verbo está na $3^{\mathrm{a}}$ pessoa, como no exemplo (2). Cunha e Cintra (1985), por sua vez, também afirmam que o pronome oblíquo SE funcionará como sujeito indeterminado quando o pronome estiver junto à $3^{\mathrm{a}}$ pessoa de verbos intransitivos ou de transitivos (diretos e indiretos) tomados intransitivamente, como em (3).

(1) "Abre-se às dez." (BECHARA, 2004, p. 177)

(2) a. "Ali trabalhava-se com prazer." (CEGALLA, 2010, p. 562)

b. "Trata-se de indivíduos aproveitadores." (CEGALLA, 2010, p. 563)

(3) a. "Vive-se ao ar livre, come-se ao ar livre, dorme-se ao ar livre." (CUNHA; CINTRA, 1985, p. 298)

b. "Martelava-se, serrava-se, acepilhava-se." (CUNHA; CINTRA, 1985, p. 298)

A partir das abordagens e exemplos mostrados, percebemos que os gramáticos apresentam classificações semelhantes para o SEIndeterminado, destacando a ocorrência desse tipo de SE em sentenças com verbos intransitivos na $3^{\text {a }}$ pessoa. A partir disso, podemos afirmar que, em uma abordagem tradicional, o SE-Indeterminado é caracterizado como aquele que ocorre em orações com o verbo flexionado na $3^{\mathrm{a}}$ pessoa, intransitivos, transitivos indiretos (2b).

Na perspectiva da GG, as discussões acerca do SE-Indeterminado buscam caracterizar esse clítico a partir do aspecto argumental e da atribuição de caso nominativo. Assim, nas discussões de Brito, Duarte e Matos (2003), Galves (1986), Nunes (1990) e Gomes (2007), existem semelhanças e divergências de posicionamentos dos autores quanto ao SE-Indeterminado como sujeito da sentença. Galves (1986) defende o caráter argumental do clítico; para a autora, nas estruturas com

\footnotetext{
${ }^{4}$ Os grifos nos exemplos são nossos.
} 
v. 7 (2)

$151-169$ ago/dez 2017

indeterminação do sujeito, o clítico está relacionado à posição de sujeito e SE recebe o caso nominativo. Análise semelhante é também encontrada em Brito, Duarte e Matos (2003) e Gomes (2007). Nunes (1990), por sua vez, argumenta que a indeterminação do sujeito se dá pela ligação anafórica entre o pronome de referência arbitrária obrigatoriamente nulo, que ocupa a posição do sujeito, e o pronome clítico SE que recebe o caso nominativo, tal ligação precisa envolver apenas um papel temático para formar a relação de indeterminação.

Outro tipo de SE relacionado a função sujeito é o SE-Passivo que, no âmbito tradicional, é caracterizado como partícula apassivadora quando serve para indicar que a sentença está em voz passiva sintética. Bechara (2004) classifica o SE como um pronome apassivador a partir de um critério semântico, levando em consideração o fato de o sujeito não ser animado, o que o faz um sujeito paciente ao invés de agente, como no exemplo (4). Já Cegalla (2010) caracteriza esse tipo de SE a partir de um critério sintático, pois, para ele, o SE funciona como um pronome apassivador quando forma a voz passiva pronominal ao se juntar a verbos transitivos diretos como em (5). Em outra definição, conforme Cunha e Cintra (1985), em frases do tipo (6), os elementos sublinhados na sentença (casas e móveis) são considerados os sujeitos dos verbos destacados, o que, para eles, caracteriza essas construções como passivas pronominais.

(4) "O banco só se abre às dez horas." (BECHARA, 2004, p. 177)

(5) "Devolveram-se as terras aos legítimos donos." (CEGALLA, 2010, p. 562)

(6) a. "Vendem-se casas." (CUNHA E CINTRA, 1985, p. 299) b. "Compram-se móveis." (CUNHA E CINTRA, 1985, p. 299)

Com essas definições e exemplos, observamos que os gramáticos constroem suas concepções a respeito de SE-Passivo a partir de critérios semânticos e sintáticos. Apesar de se tratarem de definições diferentes, podemos inferir a partir do exposto que nas gramáticas tradicionais as construções com SE-Passivo ocorrem na presença de verbos transitivos diretos (como abrir, devolver, vender e comprar), em que o verbo, em $3^{\mathrm{a}}$ pessoa, concorda em número com seu complemento, com isso, podemos constatar que, além do tipo de verbo, a concordância é o aspecto determinante para a caracterização do SE como uma partícula apassivadora. 
Em discussões no âmbito da GG, a caracterização do SE-Passivo, assim como a do SE-Indeterminado, leva em consideração o estatuto argumental desse pronome e, consequentemente, a atribuição de caso, dessa vez caso acusativo. Pensando nisso, cada autor apresenta definições distintas a respeito do SE-Passivo, mas, em relação ao estatuto argumental do SE-Passivo, é possível estabelecermos semelhanças nessas definições. Deste modo, enquanto Nunes (1990) afirma que o SE-Passivo recebe o caso acusativo do argumento externo do núcleo do sintagma verbal (V); Galves (1986), Brito, Duarte e Matos (2003) e Gomes (2007) não consideram o SE-Passivo como argumento externo de $\mathrm{V}$, pois, para esses autores, o caso acusativo não é atribuído ao SE-Passivo, sendo este clítico um morfema responsável por mudar a valência verbal acusativa para inacusativa.

Passando para o SE associado à posição e à função do complemento verbal a relação com a função sujeito permanece. Como pronome reflexivo o SE representa uma ação que é praticada e sofrida pelo sujeito, assim, o pronome SE referenciará o sujeito e será o objeto do verbo transitivo na oração. De acordo com Bechara (2004), as construções com SE-Reflexivo são caracterizadas pelo pronome como objeto (direto e indireto), representando, simultaneamente, o mesmo referente do sujeito, como no exemplo (7). Cegalla (2010) apresenta alguns contextos em que o pronome SE funcionará como um pronome reflexivo, sendo estes: pronome reflexivo com a função sintática de objeto direto de verbos reflexivos, como em (8a); pronome reflexivo com a função de objeto indireto de verbos reflexivos, como em (8b); pronome reflexivo recíproco, como em (8c); pronome reflexivo e objeto indireto de verbos reflexivos recíprocos, como em (8d) e pronome reflexivo como sujeito de um infinitivo, como em (8e). Finalmente, segundo Cunha e Cintra (1985), o pronome reflexivo expressa o objeto direto ou indireto quando este representa a mesma coisa que o sujeito do verbo, exemplo (9).

(7) "João se banha." (BECHARA, 2004, p.176)

(8) a. "Se você está doente, trate-se." (CEGALLA, 2010, p. 562)

b. "O rapaz dá-se muita importância." (CEGALLA, 2010, p. 562)

c. "Os dois amam-se como irmãos." (CEGALLA, 2010, p. 562)

d. "Os dois deram-se provas de profunda amizade." (CEGALLA, 2010, p. 562)

e. "O cego deixa-se levar pelo guia." (CEGALLA, 2010, p. 562)

(9) "Ele vestiu-se rapidamente." (CUNHA E CINTRA, 1985, p. 272) 
v. 7 (2)

151-169 ago/dez 2017

Nas definições discutidas, observamos que todos os gramáticos, basicamente, caracterizam o SE-Reflexivo como aquele que exerce a função sintática de objeto direto e indireto de verbos reflexivos a partir dos exemplos apresentados por eles. De uma forma geral, podemos afirmar que, em um plano tradicional, as construções com SE-Reflexivo podem ser definidas como aquelas em que o pronome SE representa o sujeito e o objeto ao mesmo tempo, contudo exerce a função sintática de objeto direto ou indireto na oração.

No ponto de vista da GG, as abordagens de Brito, Duarte e Matos (2003) e de Gomes (2007) para o SE-Reflexivo, também, caracterizam esse tipo de SE por seu caráter argumental. Apesar de pouco semelhantes, essas definições partilham da ideia que o SE, nesse tipo de oração, é argumental, ou seja, exerce a função de um argumento, neste caso, argumento interno (complemento), recebendo o caso acusativo.

\section{A sintaxe do SE na história do Português}

Na história do Português, o clítico SE, como os demais tipos de clíticos, apresenta variação quanto a sua ordem proclítica e enclítica, sendo um aspecto revelador de propriedades gramaticais na diacronia do português. Além da sua ordem, a função sintática que o pronome exerce na sentença pode apontar mudanças na gramática do Português. Galves (2001) nos chama a atenção para o uso do SE como um fator de diferença entre o PE e o $\mathrm{PB}$, visto que neste o clítico SE, mesmo com a tendência de desaparecer da língua em todos os seus tipos, reaparece de forma compacta se distanciando do PE. No PCl, o estudo de Chociay (2003) revelou que o clítico SE favorece o uso da ênclise em um período em que a ocorrência de próclise era geral.

Os estudos de Antonelli (2007), ao descrever o percurso diacrônico do uso do clítico SE na alternância ênclise e próclise em duas variantes do Português Europeu, corroboram com a questão levantada por Galves, Britto e Paixão de Sousa (2005) de que o clítico SE favorece as sentenças com ênclise na fase intermediária do português europeu (o PCl), em contraposição com outros tipos de clíticos; e que, mais uma vez retomando Galves, Britto e Paixão de Sousa (2005), a correlação entre o clítico SE e a ordem enclítica é desencadeada pelo uso de sentenças com um sujeito da passiva que precede, imediatamente, o verbo desencadeador de tal correlação (10) (ANTONELLI, 2007). 
(10) "As cartas mandam-se lacradas para que ninguém saiba de quem são, e nem suspeite o que contêm." (ANTONELLI, 2007, p. 169)

Ao investigar o uso do SE com infinitivo no $\mathrm{PCl}$, $\mathrm{PE}$ e $\mathrm{PB}$, Cavalcante (2006) aponta as diferenças no uso desse clítico no PE e no $\mathrm{PB}$, bem como no $\mathrm{PCl}$ e no PE. De acordo com a autora, essas diferenças são desencadeadas pela natureza do pronome SE (que pode ser passivo, indefinido e impessoal) e a natureza de Agr não finito. Para ela, a associação desses dois fatores confirmará a existência de três gramáticas distintas: $\mathrm{PCl}, \mathrm{PE}$ e PB. Diante disso, o SE apresentará diferenças em seu comportamento nas gramáticas supracitadas, melhor dizendo, gramáticas distintas produzirão distintos tipos de SE, significando, pois, que "o tipo de SE está relacionado à sintaxe de uma língua" (CAVALCANTE, 2006, p. 187).

Depois de conhecermos cada tipo de SE e entendermos o comportamento sintático de cada um, bem como observar o percurso desse clítico na história do Português, na próxima seção, apresentamos a metodologia utilizada para a busca, classificação e descrição de dados com as ocorrências desses três tipos de SE em textos de autores nascidos entre os séculos XVI, XVII e XVIII.

\section{Metodologia}

Com o intuito de investigar as construções com o clítico SE em textos referentes ao $\mathrm{PCl}$ no $\mathrm{CTB}$, desenvolvemos o seguinte trabalho: selecionamos os textos referentes aos séculos XVI, XVII e XVIII, sintaticamente anotados do CTB; buscamos, automaticamente, as ocorrências com SE nesses textos; classificamos e quantificamos os dados com o auxílio das ferramentas do EXCEL.

Para este estudo, buscamos as ocorrências do SE em dez textos sintaticamente anotados de autores nascidos ${ }^{5}$ entre os séculos XVI, XVII e XVIII extraídos do CTB, cujo período compreende a gramática do $\mathrm{PCl}$. Desses 10 textos, 4 pertencem ao século XVI, sendo 2 referentes à primeira metade ${ }^{6}$ e 2 à segunda metade 73 ao século XVII, em que

5 Vale dizer que a busca dos textos pela data de nascimento dos autores se justifica na medida em que a abordagem histórica, no âmbito da GG, leva em consideração a mudança linguística como um processo de aquisição da linguagem.

${ }^{6}$ Fernão Mendes Pinto (1510) e Diogo do Couto (1547).

7 Luis de Sousa (1556) e Manuel de Galhegos (1597). 
v. 7 (2)

151-169 ago/dez 2017

1 é referente à primeira metade8 e 2 à segunda metadeg e os outros 3 ao século XVIII e, assim como no século XVII, 1 compreende a primeira metade do século10, enquanto os demais compreendem a segunda metade11. Após a seleção dos textos no CTB, iniciamos o levantamento dos dados por meio do mecanismo de busca automática Corpus-Search ${ }^{12}$. Assim, fizemos o download dos arquivos de texto disponíveis no site do Tycho Brahe e elaboramos duas queries para a busca, uma para a busca de SE-nominativo (indeterminado e passivo) e a outra para SE-acusativo (reflexivo). Através da construção de uma query, critérios de busca foram estabelecidos delimitando-se a ordenação e a relação dos constituintes.

Com a busca, foram levantadas cerca de 1479 ocorrências de SE-nominativo e 972 de SE-acusativo. Dessas ocorrências, excluímos os contextos de mesóclise, os com verbos infinitivos, gerúndios e particípios, considerando apenas os verbos finitos nos modos indicativo e subjuntivo, e com os verbos ser, estar, haver e ter (no sentido de existir). Após essa seleção, os dados foram exportados para planilhas do EXCEL, sendo submetidos a fatores pré-estabelecidos de classificação, tais como: tipo de oração (Principal V1 e Principal V2, Coordenada dependente e Coordenada não dependente ou Subordinada); posição do 'SE' diante do verbo (SE-V próclise, V-SE ênclise, SE-X-V próclise com interpolação de constituintes); função/tipo (SE-Indeterminado, SE-Passivo ou SE-Reflexivo), verbo; tipo de predicado (Simples ou Complexo), modo verbal (indicativo, subjuntivo, gerúndio ou particípio), contexto sintático (posição pré-verbal1/ posição pré-verbal2/ posição alta do verbo - do clítico - elementos interpolados ou posição baixa do verbo - clítico); elemento pré-verbal e elemento interpolado. Em seguida, os dados foram quantificados a partir de frequência simples, os quais são descritos na próxima seção.

\section{As construções com SE no Português Clássico: descrição de dados}

Com a classificação e quantificação dos dados, nos resultados gerais, verificamos um total de 1877 ocorrências de SE com verbos

\footnotetext{
8 Padre A. Vieira (1608).

9 Maria do Céu (1658) e André de Barros (1675)

${ }^{10}$ Cavaleiro de Oliveira (1702).

${ }^{11}$ José Daniel Rodrigue (1757) e Almeida Garret (1799).

${ }^{12}$ O Corpus-Search é uma ferramenta de busca automática capaz de realizar pesquisas sintáticas em corpus anotado no formato Penn TreeBank (CORPUS-SEARCH, 2009).
} 
finitos nas posições de próclise (SE-V), ênclise (V-SE) e próclise com interpolação de constituintes $(\mathrm{SE}-\mathrm{X}-\mathrm{V})^{13}$, sendo 736 ocorrências no século XVI, 671 no século XVII e 470 no século XVIII. O SE-Passivo (11) é o que apresenta maior número de ocorrências nos três séculos, 1120 dados de SE-Passivo, sendo 405 no século XVI, 477 no XVII e 238 no século XVIII. O SE-Reflexivo (12) representa o segundo maior número de ocorrências, contabilizando 445, sendo 156 atestadas no século XVI, 135 no XVII e 154 no XVIII. Por fim, o SE-Indeterminado (13) que, no total, é o tipo de SE com o menor número, 312 ocorrências, sendo 175 no século XVI, 59 no XVII e 78 no XVIII.

(11) "Onde todos os talentos se aperfeiçêam." (Garret, 1799)

(12) "viu se com ele." (Luis de Sousa, 1556)

(13) "Não se fez assi com Bertolameu." (Luis de Sousa, 1556)

A partir dos resultados gerais, separamos e descrevemos o comportamento de cada tipo de SE a partir do tipo de oração. Assim, os dados foram descritos, separadamente, em orações principais neutras, em orações subordinadas e em coordenadas dependentes e não dependentes. Neste artigo, como recorte metodológico, apresentamos os resultados relativos ao contexto de orações principais neutras, por este ter sido o mais significativo na pesquisa.

Para a análise da relação do tipo de SE e da posição em orações principais, separamos no contexto às orações principais neutras, ou seja, orações introduzidas por constituintes neutros (que não condicionam a próclise ou a ênclise obrigatória). Nestes casos, o clítico SE é bastante produtivo tanto em próclise sem interpolação (14) quanto em ênclise (15). O mesmo não ocorre com o clítico afastado do verbo, posição de interpolação (16).

(14) "Um mancebo ateniense, nobre, galã e rico, se condenou por desatino..." (Cavaleiro de Oliveira, 1702)

(15) "Chegandoa@@a igreja, e bem moído e cansado, desculpou se com os companheiros..." (Luis de Sousa, 1556)

(16) "De umas se não sabem os logares onde estiveram..." (Antonio Vieira, 1608)

${ }_{13}$ Na estrutura SE-X-V, "X" corresponde a qualquer constituinte (adjunto, negação, outro clítico etc.) interpolado entre o SE e o verbo. 
v. 7 (2)

$151-169$ ago/dez 2017

162

A relação entre ordem e função do SE

Em orações proclíticas, como podemos verificar no gráfico 1, nos séculos XVI e XVII (mais precisamente nos anos de 1500 a 1600), há uma preferência pelo uso do SE-Passivo, com frequência sempre superior a dos demais tipos de SE (diferença maior que $20 \%$ entre o SE passivo e o reflexivo, tendo o SE indeterminado como o segundo mais frequente, entre o passivo e o reflexivo, no período. A ordem da frequência muda no final do século XVIII, estreitando a diferença da frequência entre o SE passivo e o reflexivo, passando o SE-Reflexivo a superar a frequência do SE-Indeterminado na primeira metade do século, para depois superar, inclusive, a frequência do SE-Passivo nas estruturas proclíticas em orações principais neutras nos textos da segunda metade do século (17501799). Deste modo, o resultado sugere uma mudança relacionada ao tipo de SE nas estruturas proclíticas no contexto das orações principais neutras.

Gráfico 1- Tipos de SE em estruturas proclíticas (SE-V) em orações principais neutras.

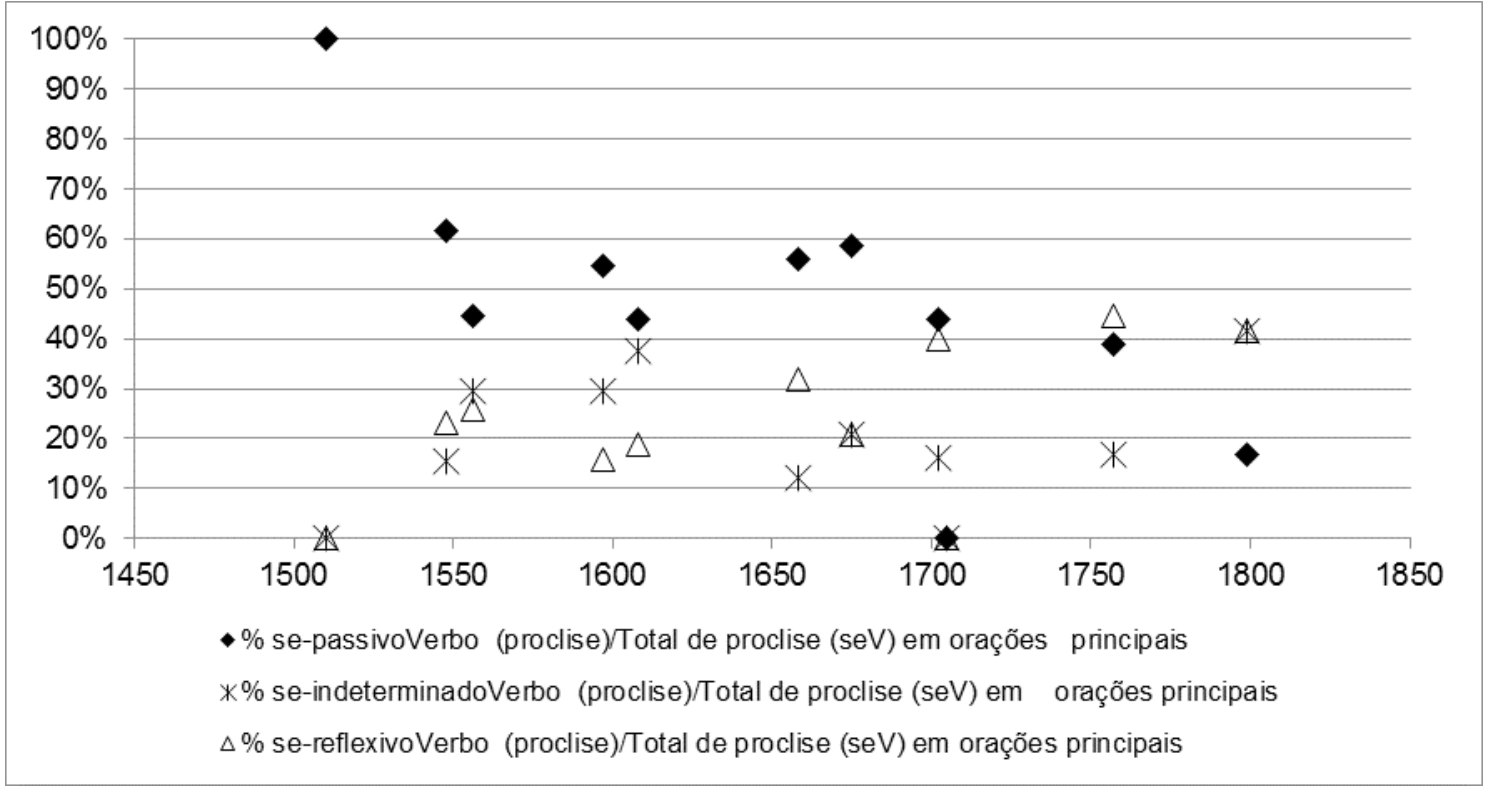

Nas construções enclíticas (Gráfico 2), há uma pequena variação na preferência pelo tipo de SE ao longo do tempo. De maneira geral, o SE-Passivo mantém sua frequência na faixa dos 50\% desde a segunda metade do século XVI até o final do século XVIII, com alguns pontos destoantes (superior nos anos de 1608 e $1675,82 \%$ e $72 \%$ respectivamente, e inferior no ano 1705). O SE-Indeterminado é atestado em todo o período a partir da segunda metade do século XVI, porém com grande oscilação em sua frequência que vai de 2\% a 51\% com ausência de progressão linear. Já o SE-Reflexivo é atestado em estruturas enclíticas apenas entre a segunda metade do século XVI e século XVII, sendo sua frequência sempre inferior a 44\% nesse período, com média de 31\%. 
Gráfico 2- Tipos de SE em estruturas enclíticas (V-SE) em orações principais neutras.

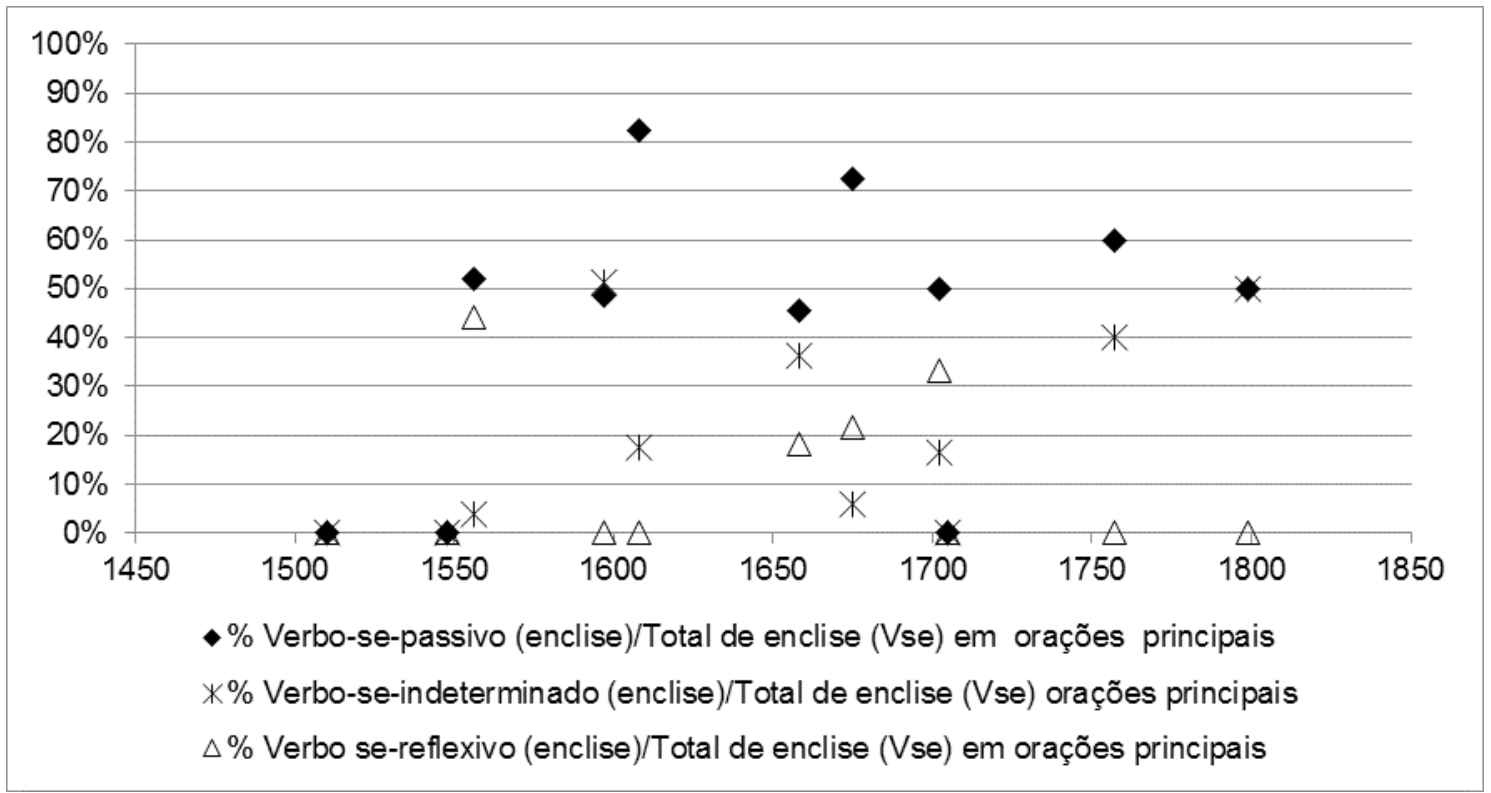

A interpolação em orações principais, gráfico 3, é quase que exclusivamente atestada com SE-Passivo em orações principais nos três séculos referentes ao período do PCl. Apenas no texto de André de Barros (1675) dois casos de interpolação com SE-Reflexivo foram atestados. Nos dados levantados, a não adjacência entre o pronome clítico SE e o verbo em orações não dependentes neutras é bastante marginal em relação às demais ordenações (apenas 20 casos para todo o período contra 234 casos de próclises e 220 casos de ênclise no mesmo contexto sintático). Os elementos que aparecem entre o SE e o verbo, são outros clíticos e o operador de negação "não".

Gráfico 3 - Tipos de SE em estruturas com interpolação (SE-X-V) em orações principais neutras.

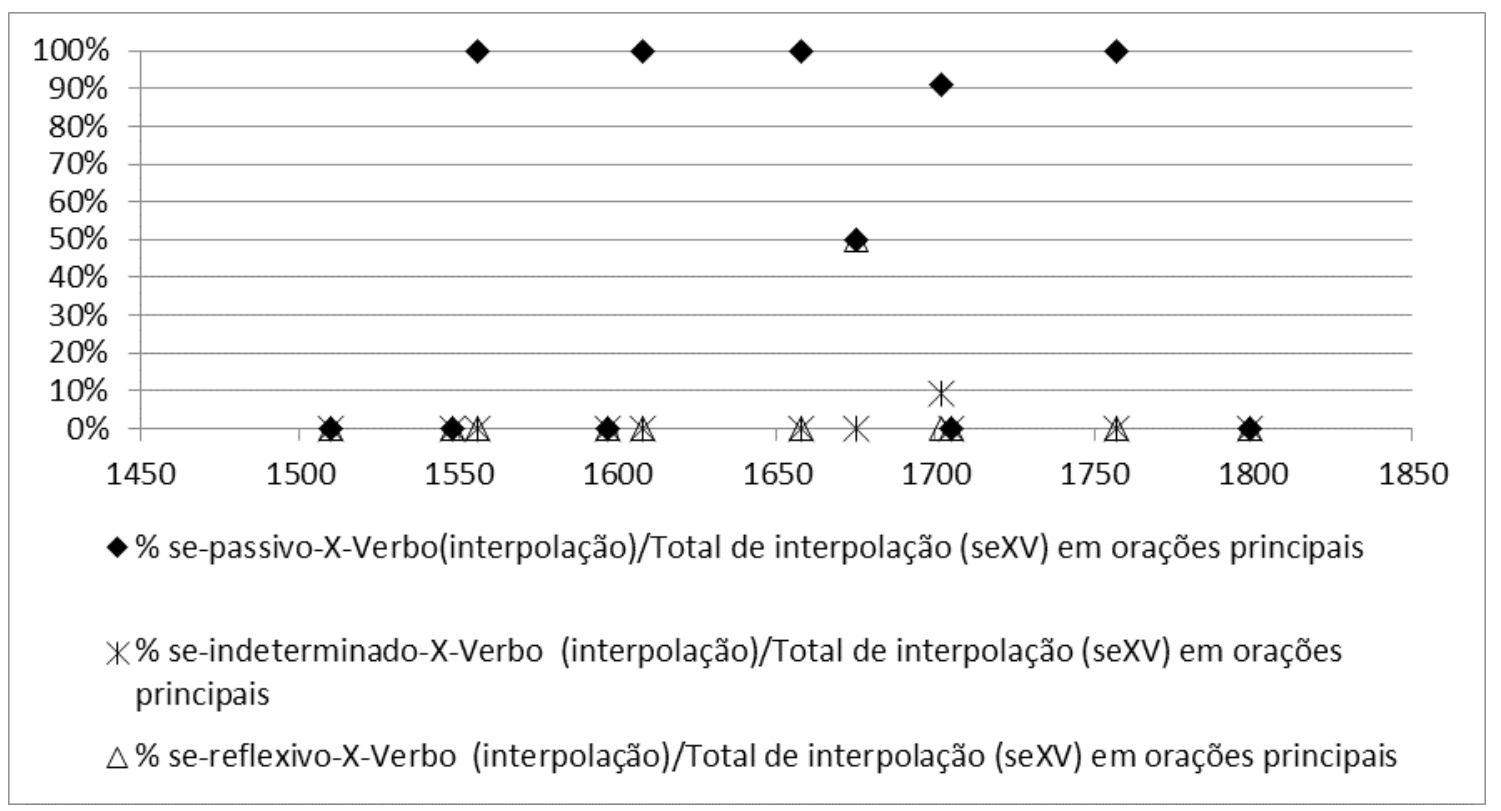


v. 7 (2)

$151-169$ ago/dez 2017

Ao compararmos as ocorrências de SE nos contextos de próclise e de ênclise, podemos interpretar que o SE relacionado à função de sujeito (SE-Passivo e SE-Indeterminado) e o SE relacionado à função de objeto (SE-Reflexivo) ocorrem sem preferências tanto em estruturas proclíticas quanto em estruturas enclíticas nas orações principais neutras nos séculos XVI e XVII, havendo uma mudança no século XVIII, observada nas estruturas proclíticas em relação às estruturas enclíticas. No século XVIII, o tipo de SE parece ser relevante, uma vez que o SEPassivo e o SE-Indeterminado são os tipos exclusivos de SE nas estruturas enclíticas, com médias de frequência $65 \%$ e $45 \%$, respectivamente, e que o SE-Reflexivo (clítico com a função de objeto) é exclusivo das estruturas proclíticas, sendo inclusive sua frequência superior a dos demais tipos de SE em próclise, média de $43 \%$ em face aos 33\% e 28\% de média de frequência para o SE-Passivo e o SE-Indeterminado. Assim, concluímos que nos contextos de variação próclise e ênclise o fator tipo de SE pode influenciar a sua colocação nos textos dos autores nascidos no século XVIII.

A ordem de SE-Passivo em orações principais

Em particular, as ocorrências de SE- Passivo em orações principais mudam quanto à preferência da ordem relativa ênclise e próclise ao longo dos séculos, conforme podemos notar no gráfico 4:

Gráfico 4- Posição relativa de SE-Passivo em orações principais neutras.

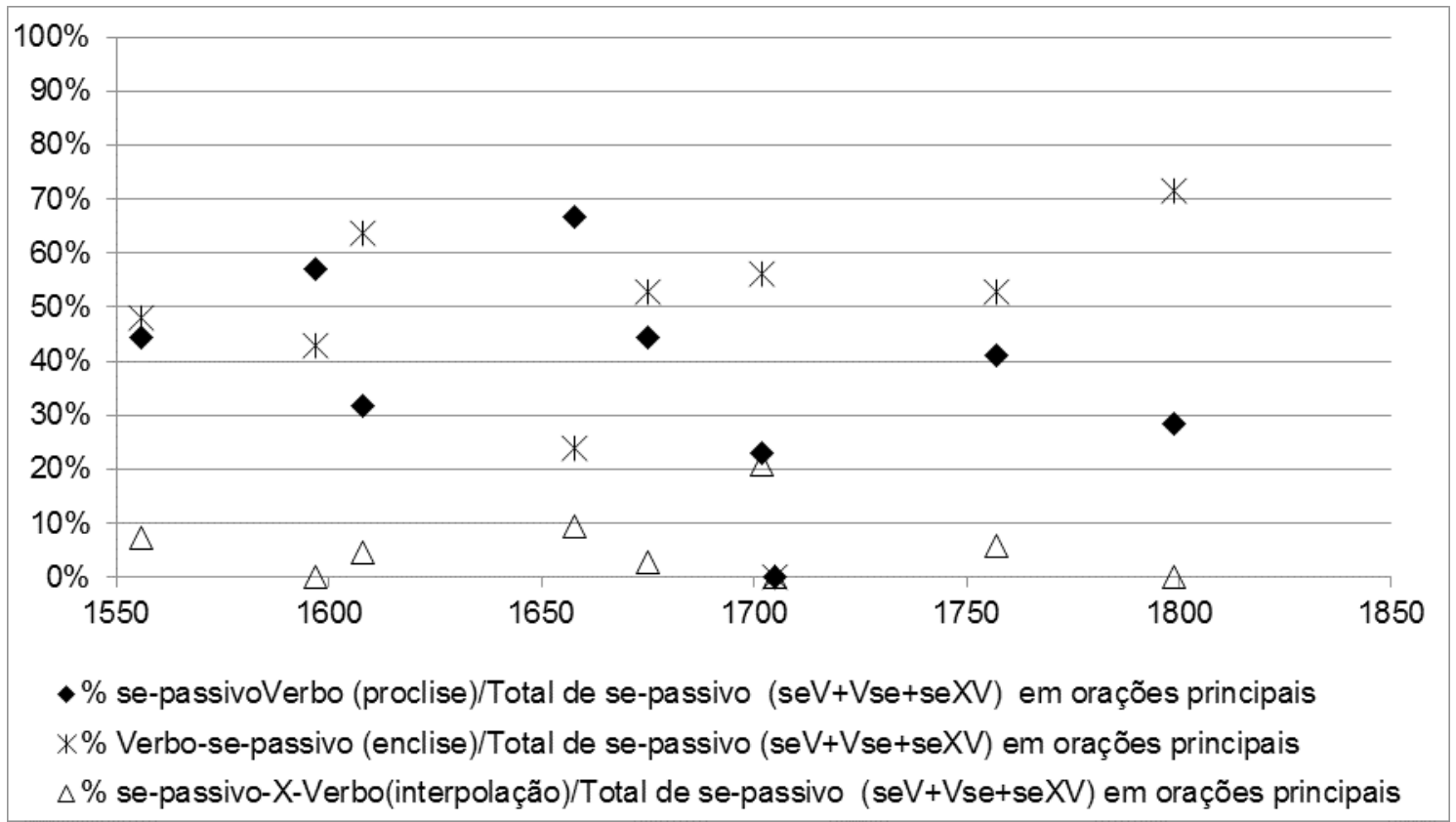


Nos séculos XVI e XVII o SE passivo é mais frequente nos contextos de próclise (17) e no XVIII nos contextos de ênclise (18), corroborando as hipóteses de Galves, Namiuti e Paixão de Sousa (2006) e Antonelli (2007), portanto a mudança da ordem preferencial do SE, de próclise para a ênclise, nesse tipo de oração, segue a mudança dos demais clíticos, pronomes dativos e acusativos, nesse mesmo período. Todavia a frequência de ênclise do SE-Passivo, apesar de ser normalmente inferior à da próclise nos textos do período clássico, é extremamente superior à frequência global da ênclise, considerando todos os pronomes clíticos, se comparada com os resultados de Galves, Britto e Paixão de Sousa (2005) atestados para o mesmo período. Dessa forma, tal resultado nos leva a concluir que o SE-Passivo contribui para o aumento da frequência de ênclise nos textos representativos do $\mathrm{PCl}$, comprovando de uma só vez as hipóteses de Chociay (2003), Cavalcante (2006) e Antonelli (2007).

(17) "bem se vê, há de ter sua costella hespanhola..." (Garret, 1799)

(18) "A casa fez- -se este anno." (Garret, 1799)

A ordem de SE-Indeterminado em orações principais

Por sua vez, as estruturas com SE- Indeterminado são bastante inferiores em relação ao SE-Passivo no $\mathrm{PCl}$ em orações principais, porém, ao observarmos apenas os casos com SE-Indeterminado, verificamos que este possui o mesmo comportamento do SE-Passivo com relação à posição na estrutura da sentença, conforme podemos notar no gráfico 5:

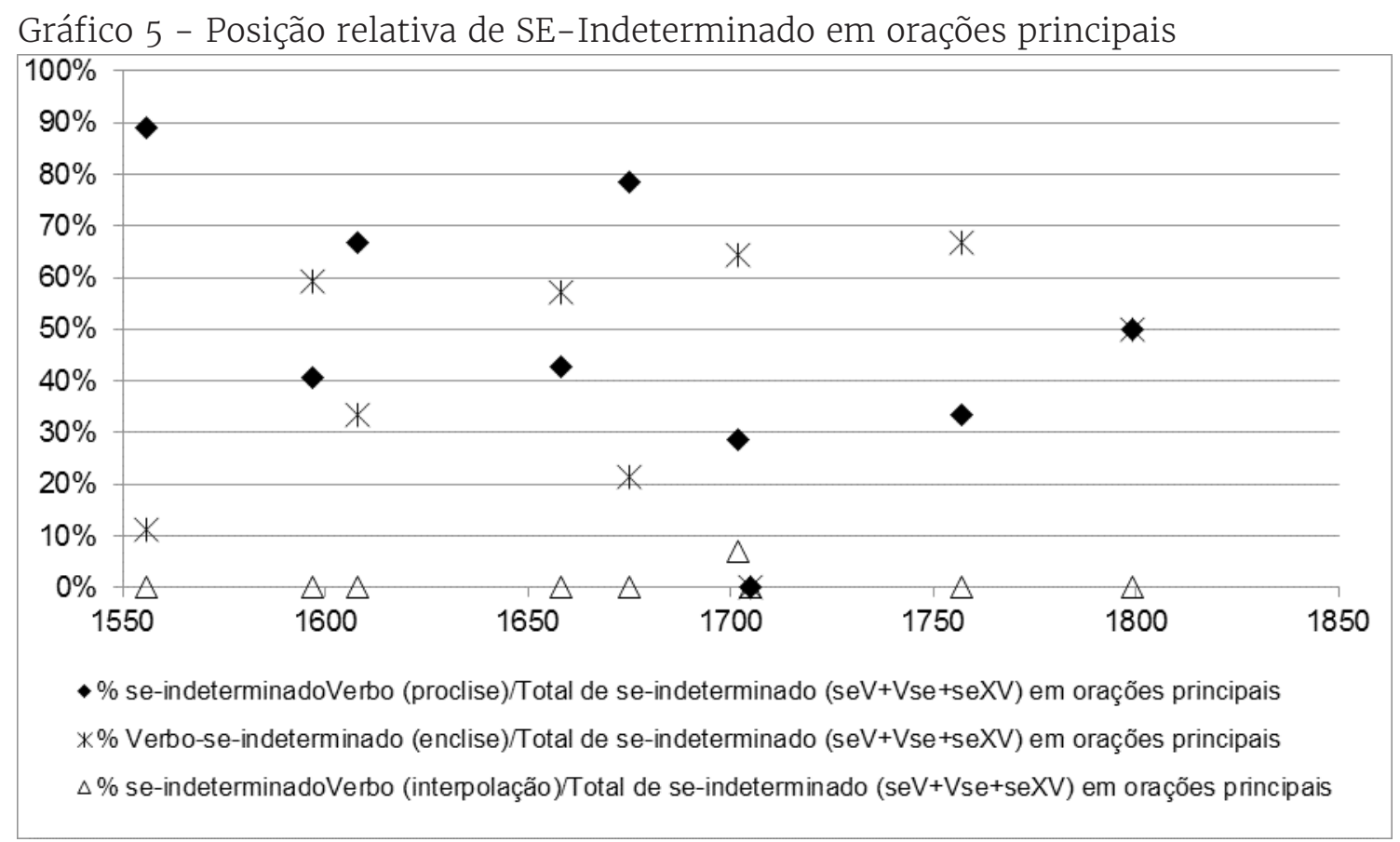


v. 7 (2)

151-169 ago/dez 2017

O SE-Indeterminado é mais frequente em estruturas proclíticas (19), porém as estruturas enclíticas (20) não são marginais, como nos casos com SE-Passivo. A frequência de ênclise de SE-Indeterminado se mantém na faixa média dos 50\% em todo o período, com alguns pontos destoantes. O SE-Indeterminado, nas estruturas de próclise com interpolação (21), é menos frequente que o passivo, só há 1 (uma) ocorrência desse tipo no início do século XVIII.

(19) "assim se executava já, e comporiam seis, ou sete aldeias..." (André de Barros, 1675)

(20)“Pol@@otemporald@@oconvento matava se pouco,inda que não tinha descuido..." (Luis de Sousa, 1556)

(21) "Chegando este com prontidão, e não estando vestido o paciente, se lhe mandou dizer que esperasse um momento..." (Cavaleiro de Oliveira, 1702)

A ordem de SE-Reflexivo em orações principais

Diferente dos tipos de SE relacionados à função sujeito, o SEReflexivo, que desempenha a função de objeto na sentença, segue um padrão proclítico com frequência bastante superior à da ênclise na linha do tempo, conforme podemos notar no gráfico 6:

Gráfico 6- Posição relativa de SE-Reflexivo em orações principais

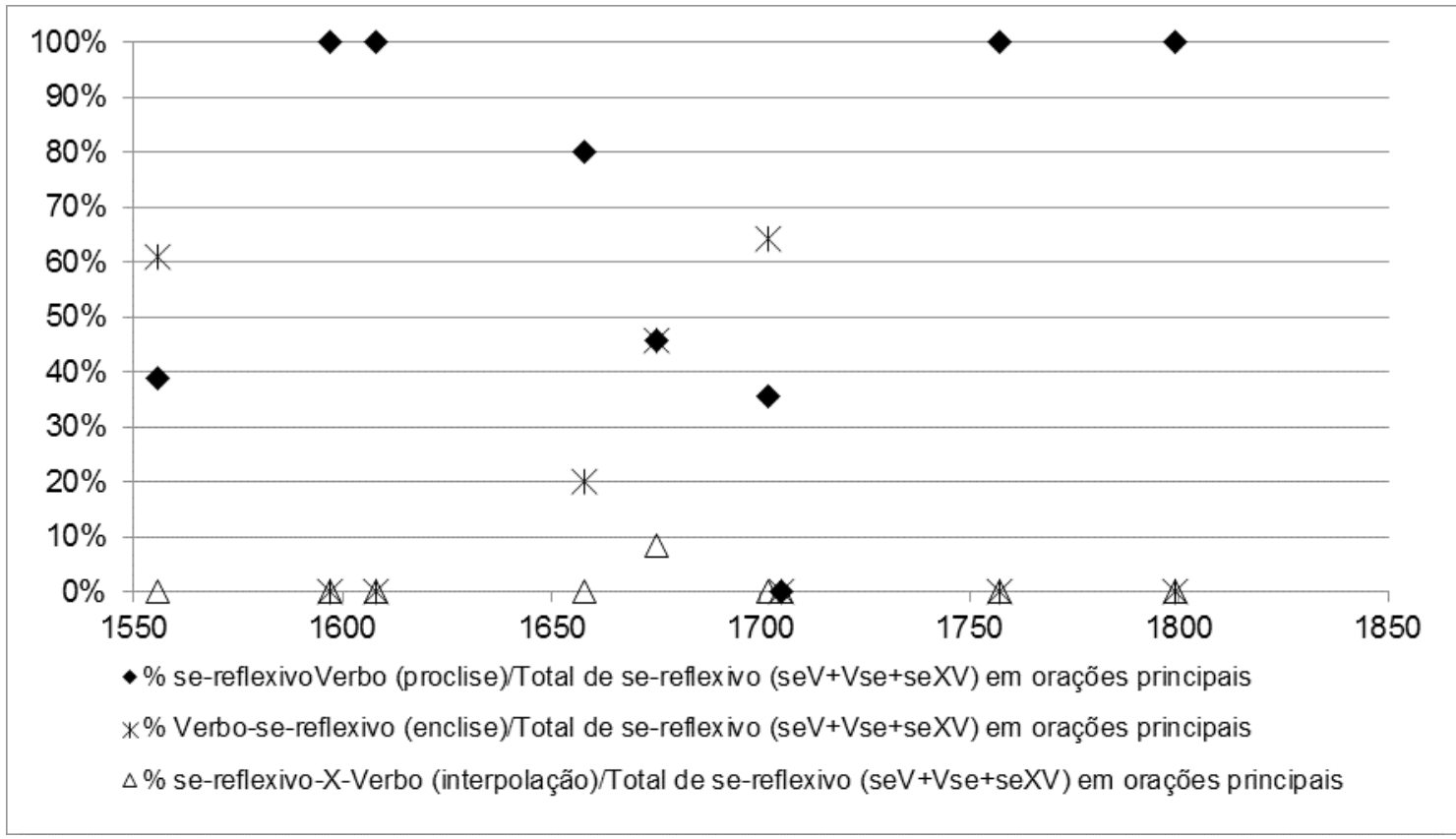


Assim, a próclise (22) com esse tipo de SE pode ser considerada categórica na maioria dos textos, sendo a ênclise (23) nula na maioria dos textos (nenhuma ocorrência). Em relação à ordem $\mathrm{SE}-\mathrm{X}-\mathrm{V}$, só verificamos uma ocorrência de SE-Reflexivo em orações principais (24).

(22) O próprio Marte se viu cativon@ @aquele dia em que foi amante..." (Cavaleiro de Oliveira, 1702)

(23) "Paralhe suceder tudo melhor ajudava se de um santo exercício." (Sousa, 1556)

(24) "Ad@@o Grande VIEIRA ainda se não contentava com rebater estas lisonjasd@@a fortuna." (André de Barros, 1675)

Com a descrição das ocorrências de SE-Indeterminado, SEPassivo e SE-Reflexivo em orações principais neutras, contexto de variação na posição do pronome em relação ao verbo, destacamos, quatro resultados importantes a respeito do uso de SE, sendo esses: 1) a mudança na ordem proclítica para enclítica do SE-Passivo a partir do século XVIII, 2) a mudança na preferência do uso de SE-Passivo por SEIndeterminado e SE-Reflexivo em posição proclítica a partir de 1700; 3) a preferência de SE com função de sujeito (passivo e indeterminado) na posição de ênclise; e 4) a preferência da posição proclítica nas construções de SE-Reflexivo.

\section{Considerações Finais}

A partir da descrição dos tipos de SE em orações principais neutras, observamos que os tipos de SE relacionados à função sujeito são mais frequentes em todas as posições no contexto de orações principais em todo o período relacionado ao $\mathrm{PCl}$, tendo a relação de frequência trocada nas estruturas proclíticas nos textos do século XVIII, dando lugar ao SE-Reflexivo que tem a função de objeto. Dos dois tipos de SE ligados diretamente à função de sujeito, o SE-Passivo é o mais produtivo no $\mathrm{PCl}$, podendo ocorrer, inclusive, em estruturas com interpolação - colocação não atestada para os demais tipos de SE. Desta forma, os resultados trouxeram evidências importantes para se comprovar a hipótese de que existe alguma relação entre o tipo de SE e sua ordem ao revelar que os tipos de SE relacionados à função sujeito são exclusivos nas estruturas enclíticas, o SE-Reflexivo (clítico com a função de objeto) é exclusivo das estruturas proclíticas, sendo inclusive sua frequência superior a dos 
v. $7(2)$

$151-169$ ago/dez 2017

demais tipos de SE em próclise nesse contexto das orações principais antecedidas por constituintes neutros no século XVIII, fator que também constitui evidência que corrobora a hipótese de mudança e periodização de Galves, Namiuti e Paixão de Sousa (2006).

Destarte, os resultados que apontam a preferência pelos tipos de SE relacionados à função sujeito (passivo e indeterminado) em posição enclítica e a preferência pelo SE-Reflexivo, com função de objeto, em estruturas proclíticas constituem pistas para estabelecermos uma relação entre a posição e o tipo/função do SE. Assim, os tipos de SE com função de sujeito estariam relacionados à posição enclítica, enquanto que o SE com função de objeto estaria relacionado à posição proclítica. Para concluirmos, vale dizer que tais pistas são importantes para estabelecermos essa relação, contudo, são necessárias mais investigações, nesse âmbito, para comprovar, de fato, essa relação entre a ordem do clítico SE e a sua função sintática.

\section{Referências}

ANTONELLI, André Luís. O clítico SE e a variação ênclise/próclise do Português Médio ao Português Europeu Moderno. 2007. 185f. Dissertação (Mestrado em Linguística) Instituto de Estudos da Linguagem. Universidade Estadual de Campinas, Campinas.

BECHARA, Evanildo. Moderna Gramática Portuguesa. 37. ed. Rio de Janeiro: Lucerna, 2004.

BRITO, A. M.; Duarte, I.; MATOS, G. A Tipologia e distribuição das expressões nominais. In: MATEUS, Maria Helena Mira, et al. Gramática da Língua Portuguesa. Lisboa: Caminho, 2003, p. 826 - 848.

CAVALCANTE, Silvia Regina de Oliveira. 0 uso de se com infinitivo na História do Português: Do Português Clássico ao Português Europeu e Brasileiro Moderno. 2006. 206f. Instituto de Estudos da Linguagem. Universidade Estadual de Campinas, Campinas.

CEGALLA, Domingos. Paschoal. Novíssima gramática da língua portuguesa. 48. ed. São Paulo: Companhia Editora Nacional, 2010.

CHOCIAY, Luciane. 0 papel do tipo de clítico na ordem proclítica ou enclítica no Português Clássico. Campinas: UNICAMP, IEL (relatório), 2003.

CORPUS SEARCH. Corpus Search Users Guide. 2009. Disponível em: < http:// corpussearch.sourceforge.net/CS-manual/Contents.html>. Acesso em: 30 nov. 2015.

CUNHA, Celso; CINTRA, Lindley. Nova gramática do português contemporâneo. Rio de Janeiro: Nova Fonteira, 1985.

GALVES, Charlotte Marie Chambelland. Aluga-(se) casas: um problema de 
sintaxe portuguesa na teoria de regência e vinculação. Campinas: Preedição 2, 1986. Unicamp, 2001.

Ensaios sobre as gramáticas do português. Campinas: Editora da

.; BRITTO, Helena de Sousa.; PAIXÃO DE SOUSA, Maria Clara. The change in clitic placement from Classical to Modern European Portuguese: Results from the Tycho Brahe Corpus. Journal of Portuguese Linguistics, Lisboa, v.4, n.1, p.39-67, 2005.

.; NAMIUTI, Cristiane.; PAIXÃO de SOUSA, Maria Clara. Novas perspectivas para antigas questões: revisitando a periodização da língua portuguesa. In: ENDRUSCHAT, A.; KEMMLER, R.; SCHÄFER-PRIEB, B. (Orgs.). Grammatische Structuren des Europäischen Portugiesisch. Turbigen: Calapinus Verlag, 2006.

GOMES, Raimundo Francisco. 0 se indeterminador do sujeito, apassivador e reflexivo: uma leitura morfossintático-semântica. 2007.186f. Tese (Doutorado em Letras) - Pontifícia Universidade Católica do Rio Grande do Sul, Porto Alegre - RS.

LOPES, Eloísa Maiane Barbosa. Um estudo diacrônico sobre a ordem e a função do clítico SE no Português Clássico. 2016. 170f. Dissertação (Mestrado em Linguística) - Universidade Estadual do Sudoeste da Bahia, Vitória da Conquista.

NUNES, Jairo Morais Nunes. O famigerado se: uma análise sincrônica e diacrônica das construções com se apassivador e indeterminador. 1990. $172 \mathrm{f}$. Dissertação (Mestrado em Linguística) - Instituto de Estudos da Linguagem. Universidade Estadual de Campinas, Campinas.

UNIVERSIDADE DE CAMPINAS. Corpus Histórico Anotado do Português Tycho Brahe. 1998. Disponível em: <www.tycho.iel.unicamp.br/ tycho/corpus $>$. Acesso em: 2015.

Recebido em: 12 de fev. de 2017.

Aceito em: 26 de jul. de 2017. 